\title{
Impact of Obesity in Patients with Candida Bloodstream Infections: A Retrospective Cohort Study
}

Katie E. Barber (D) · Jamie L. Wagner · Jennifer M. Miller •

Emily A. Lewis · Kayla R. Stover

Received: December 19, 2019 / Published online: February 15, 2020

(C) The Author(s) 2020

\section{ABSTRACT}

Background: Candida species are responsible for $15 \%$ of bloodstream infections, leading to prolonged hospitalizations and increased mortality. With the rise in obesity, antifungal dosing is unclear. The purpose of this study was to determine differences in clinical outcomes between obese versus non-obese patients with Candida bloodstream infections.

Methods: This retrospective cohort included adult patient's first episode of Candida bloodstream infection treated with $\geq 48 \mathrm{~h}$ of antifungal therapy between 1 June 2013 and 31 August 2019. Patients were excluded for: dual systemic antifungal therapy, polymicrobial infections, or chronic candidiasis. The primary outcome was infection-related length of stay. Secondary outcomes included: time to candidemia resolution, 30-day readmission rates, and in-hospital mortality.

Results: Eighty patients were included (28 obese; 52 non-obese). Most were male (55\%);

Enhanced digital features To view enhanced digital features for this article go to https://doi.org/10.6084/ m9.figshare.11734227.

K. E. Barber $(\bowtie) \cdot J$. L. Wagner · J. M. Miller

E. A. Lewis - K. R. Stover

Department of Pharmacy Practice, University of

Mississippi School of Pharmacy, Jackson, MS, USA

e-mail: kbarber@umc.edu median age was 54 years. Median BMI and weight were $36.3 \mathrm{~kg} / \mathrm{m}^{2}$ and $103 \mathrm{~kg}$ versus $20.4 \mathrm{~kg} / \mathrm{m}^{2}$ and $61 \mathrm{~kg}$, respectively $(p<0.01)$. Baseline characteristics were comparable. $C$. albicans was isolated in $37.5 \%$ of cultures and $C$. glabrata in 30\%. Micafungin was utilized empirically in $72.5 \%$ of patients; obese patients received definitive micafungin more frequently $(57.1 \%$ vs. $21.2 \% ; p<0.01)$ and were treated longer (13 versus 10 days; $p=0.04$ ). Infectionrelated length of stay was 19 days in the obese patients and 13 days in the non-obese patients $(p=0.05)$. Non-obese patients had a shorter duration of candidemia (5 versus 6 days; $p=0.02$ ). In-hospital mortality was numerically higher in obese patients $(21.4 \%$ versus $13.5 \%$; $p=0.36$ ). There were no differences in 30-day readmissions between groups.

Conclusions: Worse clinical outcomes were observed for obese versus non-obese patients. Further clinical research is warranted.

Keywords: Candida; Fluconazole; Fungemia; Micafungin; Obesity 


\section{Key Summary Points}

Rates of both candidemia and obesity are increasing.

Pharmacokinetics of standard of care therapy, including fluconazole and echinocandins, are altered in obese patients though clinical correlation has not been established.

In this study, obese patients with candidemia displayed worse clinical outcomes (infection-related length of stay and duration of candidemia).

\section{INTRODUCTION}

In a nationwide surveillance study conducted from 2011 to 2014, three Candida species were listed in the top 15 causative organisms of nosocomial infections [1]. Candida albicans and C. glabrata represent the 6th and 11th leading causes of central line-associated bloodstream infections. Candida species cause nearly $15 \%$ of all bloodstream infections in hospitalized patients and contribute to prolonged hospitalizations, increased cost, and increased morbidity and mortality $[1,2]$. Mortality rates up to nearly $50 \%$ have been attributed to nosocomial candidemia with increased risk associated with delay of adequate antifungal therapy $[3,4]$.

According to the Centers for Disease Control and Prevention, approximately $40 \%$ of adults in the USA are obese; the rate of obesity has been gradually increasing over time $[5,6]$. Although fluconazole and the echinocandins are the drugs of choice for the treatment of Candida infections, pharmacokinetic studies have demonstrated that target attainment is unachievable utilizing standard dosing strategies of these agents in obese patients [7-11]. Additionally, clinical efficacy has not been established in this patient population. Therefore, the purpose of this study was to determine if a difference in clinical outcomes exists between obese and non-obese patients with Candida bloodstream infections.

\section{METHODOLOGY}

\section{Study Design, Setting, and Patient Population}

A retrospective cohort study of Candida bloodstream infections was conducted at an academic medical center and tertiary referral center. Adult patients who received $\geq 48 \mathrm{~h}$ of antifungal therapy between 1 June 2013 and 31 August 2019 with a positive blood culture for Candida were included. Eligible patients were identified utilizing TheraDoc ${ }^{\circledR}$ Clinical Surveillance (Premier, Inc., 2018). Patients were divided into two groups: obese and non-obese. Patients were excluded if they received combination antifungal therapy, had polymicrobial infections, or had chronic candidiasis. If a patient had multiple courses of candidemia, only the first episode was included in the analysis. The presented study received approval from The University of Mississippi Office of Research Integrity Institutional Review Board and conformed to the Helsinki Declaration of 1964 (as revised in 2013) concerning human and animal rights. Since the investigation was carried out through retrospective review of medical records, ethics approval was not required because of no foreseeable impact on the rights and/or welfare of subjects involved. Consent from study participants was additionally not obtained because the study solely involved retrospective review of medical records.

\section{Study Variables and Definitions}

Variables collected from the electronic health record included demographics, comorbid conditions [Charlson score and quick sequential organ failure assessment (qSOFA) score], and pharmacologic information, including time to initiation of antifungal therapy, type of antifungal therapy, antifungal dosing, antifungal frequency, and antifungal duration of therapy. Microbiology and infectious-related 
information, including source of infection, species isolated, presence of infectious diseases consultation, and presence and timing of source control were assessed. Additional data collected included infection-related length of stay (time from the first positive Candida blood culture until the day of hospital discharge), total hospital length of stay, in-hospital mortality, 30-day readmission, clinical failure, and whether the infection was healthcare associated (fungemia developed $>48 \mathrm{~h}$ after hospital admission). Obesity was defined according to the Centers for Disease Control and Prevention as a body mass index $(\mathrm{BMI}) \geq 30 \mathrm{~kg} / \mathrm{m}^{2}$ [12] Clinical failure was defined as persistently positive fungemia ( $\geq 7$ days) or development/persistence of multi-organ failure or persistently positive/increasing 1,3-beta-D-glucan concentrations plus at least one of the following: WBC $>12,000$ cells $/ \mathrm{mm}^{3}$ or $<4000$ cells $/ \mathrm{mm}^{3}$ or temperature $>38{ }^{\circ} \mathrm{C}$ or $<35^{\circ} \mathrm{C}$.

\section{Clinical Outcomes}

The primary outcome was infection-related length of stay between the obese and non-obese patient populations. Secondary endpoints included the difference in time to candidemia resolution, 30-day readmission rates, and inhospital mortality.

\section{Data Analysis}

For comparisons between the obese and nonobese groups, categorical data were analyzed utilizing Pearson's chi-square or Fisher's exact test, as appropriate, and continuous data were analyzed utilizing the Mann-Whitney $U$ test or Student's $t$ test, as appropriate. A two-sided $P$ value of 0.05 was considered statistically significant. Statistical analyses were performed using SPSS (version 24.0, IBM, Armonk, NY).

\section{RESULTS}

The cohort included 80 unique patients, with 28 patients in the obese group and 52 patients in the non-obese group. Patient characteristics are listed in Table 1 . The majority of patients were male $(55 \%)$ with a median [interquartile range] age of 53.5 [39-63] years. Baseline characteristics were comparable between the groups with the exception of weight, BMI, and presence of hypertension. The median BMI and weight were $36.3[31.7-41.3] \mathrm{kg} / \mathrm{m}^{2}$ and 102.5 [91.2-111.1] $\mathrm{kg}$ versus $20.4[17.3-25.8] \mathrm{kg} / \mathrm{m}^{2}$ and 61.4 [50.8-72.6] kg in the obese and nonobese groups, respectively $(p<0.01)$. The most commonly isolated Candida species were $C$. albicans $(37.5 \%)$ followed by C. glabrata (30\%) with no differences observed between either group. Only two cultures with $C$. krusei were isolated: one in each group. Only four isolates were identified that were fluconazole resistant or susceptible dose-dependent, with two occurring in each group of patients. Fifty-eight (73\%) patients received micafungin, $21(26 \%)$ patients received fluconazole, and 1 (1\%) patient received posaconazole. While there were no differences between groups regarding treatment selection, 16 (31\%) non-obese patients compared with 5 (18\%) obese patients received fluconazole $(p=0.211)$, and $36(69 \%)$ non-obese patients compared with $22(79 \%)$ obese patients received micafungin $(p=0.372)$. The micafungin dosage used in all patients was $100 \mathrm{mg}$ daily whereas the fluconazole dose was $400 \mathrm{mg}$ daily, which was adjusted for those with renal impairment.

The primary outcome of infection-related length of stay was 19 [10-42] days in the obese patients and 13 [8-19] days in the non-obese patients $(p=0.05)$ (Table 2). Micafungin was the most commonly utilized empiric antifungal (obese: $78.6 \%$ vs. non-obese: $69.2 \%$ ). However, obese patients remained on micafungin for definitive therapy more frequently than nonobese patients $(57.1 \%$ vs. $21.2 \% ; p<0.01)$. Additionally, obese patients were treated with definitive therapy longer than non-obese patients at 13 [10-16] days versus 10 [5-14] days $(p=0.04)$. Definitive therapy was initiated faster in obese patients: 13 [4-44] h vs. 51 [3-11] h $(p=0.03)$. There were no differences in frequency $(p=0.15)$ or timing of source control $(p=0.88)$, which occurred in $33.8 \%$ of patients at a median of 30 [12-72] h among obese and non-obese patients. However, $82.1 \%$ of obese 
Table 1 Patient demographics

\begin{tabular}{|c|c|c|c|c|}
\hline $\begin{array}{l}\text { Variable presented as \# (\%) or median } \\
\text { (IQR) }\end{array}$ & Total $(n=80)$ & Obese $(n=28)$ & $\begin{array}{l}\text { Non-obese } \\
(n=52)\end{array}$ & $p$ value \\
\hline Age (years) & $53.5[39-63]$ & $59[39.5-65]$ & $49.5[37.25-60.75]$ & 0.13 \\
\hline Sex, male & $44(55)$ & $11(39.3)$ & $33(63.5)$ & 0.04 \\
\hline \multicolumn{5}{|l|}{ Race } \\
\hline Caucasian & $32(40)$ & $10(35.7)$ & $22(42.3)$ & 0.57 \\
\hline African American & $45(56.3)$ & $17(60.7)$ & $28(53.8)$ & 0.56 \\
\hline Hispanic & $1(1.3)$ & $1(3.6)$ & $0(0)$ & 0.35 \\
\hline Other, Indian & $1(1.3)$ & $0(0)$ & $1(1.9)$ & 1.00 \\
\hline Unknown & $1(1.3)$ & $0(0)$ & $1(1.9)$ & 1.00 \\
\hline Weight & $\begin{array}{l}72.95 \\
{[57.775-94.725]}\end{array}$ & $\begin{array}{l}102.5 \\
{[91.15-111.05]}\end{array}$ & $61.4[50.775-72.6]$ & $<0.001$ \\
\hline BMI & $25.9[19.0125-33]$ & $36.3[31.65-41.275]$ & $\begin{array}{l}20.42 \\
{[17-25.7975]}\end{array}$ & $<0.001$ \\
\hline \multirow[t]{2}{*}{ Baseline SCr $(n=79)$} & \multirow[t]{2}{*}{$1.2[0.7-2.68]$} & $N=27$ & $N=52$ & \multirow[t]{2}{*}{0.23} \\
\hline & & $1.2[0.76-3.26]$ & $1.28[0.65-1.8925]$ & \\
\hline Baseline temperature, $\mathrm{C}$ & $37.2[36.7-38.675]$ & $\begin{array}{l}37.15 \\
\quad[36.625-39.025]\end{array}$ & $37.4[36.705-38.6]$ & 0.68 \\
\hline \multirow[t]{2}{*}{ Baseline white blood cells $(n=79)$} & \multirow{2}{*}{$\begin{array}{l}10,700 \\
{[6600-18,800]}\end{array}$} & $N=27$ & $N=52$ & \multirow[t]{2}{*}{0.68} \\
\hline & & $\begin{array}{l}11,000 \\
{[7000-20,800]}\end{array}$ & $\begin{array}{l}9,800 \\
{[6000-18,475]}\end{array}$ & \\
\hline Respiratory rate $>22$ & $28(35)$ & $12(42.9)$ & $16(30.8)$ & 0.28 \\
\hline GCS $<13$ & $15(18.8)$ & $7(25)$ & $8(15.4)$ & 0.29 \\
\hline$S B P<100$ & $38(47.5)$ & $12(42.9)$ & $26(50)$ & 0.54 \\
\hline qSOFA score & $1[0-2]$ & $1[0-2]$ & $1[0-2]$ & 0.60 \\
\hline Hypertension & $48(60)$ & $21(75)$ & $27(51.9)$ & 0.04 \\
\hline Neutropenic & $11(13.8)$ & $3(10.7)$ & $8(15.4)$ & 0.74 \\
\hline VTE & $17(21.3)$ & $6(21.4)$ & $11(21.2)$ & 0.98 \\
\hline \multicolumn{5}{|l|}{ Nutrition } \\
\hline Enteral tube feeds & $16(20)$ & $4(14.3)$ & $12(23.1)$ & 0.35 \\
\hline Parenteral & $28(35)$ & $13(46.4)$ & $15(28.8)$ & 0.12 \\
\hline Solid/liquid food & $36(45)$ & $11(39.3)$ & $25(48.1)$ & 0.45 \\
\hline Previous antifungal use & $12(15)$ & $7(25)$ & $5(9.6)$ & 0.10 \\
\hline Systemic corticosteroids & $8(10)$ & $5(17.9)$ & $3(5.8)$ & 0.12 \\
\hline Charlson & $3[1-5]$ & $3[1-4.75]$ & $3[1-5]$ & 0.72 \\
\hline
\end{tabular}


Table 1 continued

\begin{tabular}{|c|c|c|c|c|}
\hline $\begin{array}{l}\text { Variable presented as \# (\%) or median } \\
\text { (IQR) }\end{array}$ & Total $(n=80)$ & Obese $(n=28)$ & $\begin{array}{l}\text { Non-obese } \\
(n=52)\end{array}$ & $p$ value \\
\hline \multicolumn{5}{|l|}{ Baseline temperature } \\
\hline $36.1-38.9$ & $65(81.3)$ & $21(75)$ & $44(84.6)$ & 0.29 \\
\hline $35.1-36$ or $39-39.9$ & $13(16.3)$ & $5(17.9)$ & $8(15.4)$ & 0.76 \\
\hline$\leq 35$ or $\geq 40$ & $2(2.5)$ & $2(7.1)$ & $0(0)$ & 0.12 \\
\hline Hypotension & $24(30)$ & $5(17.9)$ & $19(36.5)$ & 0.08 \\
\hline Mechanical ventilation & $17(21.3)$ & $6(21.4)$ & $11(21.2)$ & 0.98 \\
\hline Pitt bacteremia score & $1[0-3]$ & $1[0-2.75]$ & $1[0-3]$ & 0.50 \\
\hline \multicolumn{5}{|l|}{ Suspected/documented source of infection } \\
\hline $\mathrm{CVC}$ & $8(10)$ & $4(14.3)$ & $4(7.7)$ & 0.44 \\
\hline Urine & $6(7.5)$ & $1(3.6)$ & $5(9.6)$ & 0.66 \\
\hline GI tract & $11(13.8)$ & $5(17.9)$ & $6(11.5)$ & 0.50 \\
\hline Other & $4(5)$ & $0(0)$ & $4(7.7)$ & 0.29 \\
\hline Unknown & $27(33.8)$ & $12(42.9)$ & $15(28.8)$ & 0.21 \\
\hline Healthcare-associated & $53(66.3)$ & $19(67.9)$ & $34(65.4)$ & 0.82 \\
\hline Source control & $27(33.8)$ & $8(28.6)$ & $19(36.5)$ & 0.47 \\
\hline
\end{tabular}

$B M I$ body mass index, $S C r$ serum creatinine, $C$ Celsius, GCS Glascow Coma Score, SBP systolic blood pressure, $q S O F A$ quick sequential organ failure assessment, $V T E$ venous thromboembolism, $C V C$ central venous catheter, GI gastrointestinal

Table 2 Clinical outcomes

\begin{tabular}{lllll}
\hline Variable presented as \# (\%) or median (IQR) & Total $(\boldsymbol{n}=\mathbf{8 0})$ & Obese $(\boldsymbol{n}=\mathbf{2 8})$ & Non-obese $(\boldsymbol{n}=\mathbf{5 2})$ & $\boldsymbol{p}$ value \\
\hline Infection-related length of stay (days) & $13[9-24]$ & $19[10-42]$ & $13[8-19]$ & 0.05 \\
Duration of candidemia (days) & $5[4-7]$ & $6[4-9]$ & $5[3-6]$ & 0.02 \\
30-Day readmission disposition $(n=67)$ & & $N=22$ & $N=45$ & \\
Alive, not readmitted & $53(79.1)$ & $19(86.4)$ & $34(75.6)$ & 0.36 \\
Alive, infection-related readmission & $3(4.5)$ & $0(0)$ & $3(6.7)$ & 0.55 \\
Alive, non-infection-related readmission & $6(9)$ & $2(9.1)$ & $4(8.9)$ & 1.00 \\
Dead & $4(6)$ & $0(0)$ & $4(8.9)$ & 0.29 \\
Unknown & $1(1.5)$ & $1(4.5)$ & $0(0)$ & 0.33 \\
In-hospital mortality & $13(16.3)$ & $6(21.4)$ & $7(13.5)$ & 0.36 \\
\hline
\end{tabular}


patients compared with $55.8 \%$ non-obese patients received infectious diseases consultation $(p=0.02)$.

In-hospital mortality was numerically higher in obese patients versus non-obese patients with observed rates of $21.4 \%$ vs. $13.5 \%(p=0.36)$. Clinical failure was comparable between both groups with rates of $64.3 \%$ and $75 \%$ in the obese and non-obese patients $(p=0.31)$. In subgroup analyses aimed at identifying risk factors for clinical failure, baseline WBC $(p<0.01)$, baseline respiratory rate $>22$ breaths per minute $(p=0.01)$, baseline temperature $(p<0.01)$, hematologic malignancy $(p=0.03)$, and mechanical ventilation $(p=0.02)$ were identified.

\section{DISCUSSION}

To our knowledge, this is the first report that evaluates the impact of obesity on outcomes associated with Candida bloodstream infections. Similar to reported trends in Candida epidemiology, the predominantly identified pathogens in this study were C. albicans and C. glabrata [13-15]. Obese patients had slightly more $C$. glabrata, but this number was not significant. Obesity did not impact the choice of empiric antifungal therapy, although numerically more obese patients were treated with echinocandins. However, significantly more obese patients received an echinocandin as definitive therapy. This may be explained by the higher proportion of patients in this group with C. glabrata, the almost $10 \%$ less source control in the obese group, or the higher number of infectious diseases consults in the obese group.

The results of this study are comparable to published literature on overall outcomes associated with candidemia. First, in this study, the infection-related length of stay was a median of 13 days, which is similar to a study conducted among patients in internal medicine wards [16]. Obese patients had an infection-related length of stay roughly 7 days longer than non-obese patients. Next, the duration of candidemia in this study was a median of 5 days, which is shorter than the 10 days reported in patients in an intensive care unit [17]. However, obese patients had a significantly longer duration of candidemia, which may be responsible for the longer length of stay. Finally, the overall inhospital mortality rate was $16.3 \%$, which is lower than the $83 \%$ reported in intensive care units, but falls within the range of $5-71 \%$ that has been reported otherwise [17, 18]. Although there was no statistical difference in mortality between groups, one may argue that a $7 \%$ difference in mortality may be clinically relevant.

General risk factors for candidemia have been established, but limited information is available related to risk factors for clinical failure $[16,19]$. Compared with general reports of successful treatment in $70 \%$ of patients, our rates of clinical failure of $65-75 \%$ are high [20]. This is likely due to discrepancies in definitions of success and failure between studies.

Although limited information is available on the impact of obesity in candidemia, several studies have been published related to the effect of obesity in other infectious diseases with mixed results [21-23]. In one study, obesity was associated with decreased 30-day mortality in pneumonia, but had no impact on mortality in urinary tract infections, skin infections, or bloodstream infections [21]. No differences in length of stay or requirement for intensive care were found between obese and non-obese groups. In a second study, higher BMI was associated with increased risk of all-cause mortality and organ failure in patients with gramnegative bloodstream infections [22]. Finally, in obese patients with sepsis, all-cause mortality was lower, length of stay was longer, and hospital costs were higher than in non-obese patients [23]. Taken together, these results lend support to the findings of increased mortality and length of stay in obese patients with Candida bloodstream infections that were found in this study.

This study is not without limitations. First, this study was retrospective, which is prone to selection bias and confounding variables. In this trial, all patients who met inclusion criteria during this period were included, limiting selection bias. In addition, standard definitions were used, and these were applied consistently between obese and non-obese groups. Demographics, comorbidity scores, and severity of 
illness scores were compared between groups and found to be similar, which should limit confounding variables. Next, this study was small and performed at a single center, which may limit the generalizability of these results to other centers or those with a different Candida epidemiology or patient case mix. However, the included patients were representative of obese populations, those found at academic medical centers, and those with Candida bloodstream infections.

\section{CONCLUSION}

In conclusion, obese patients had a longer infection-related length of stay, duration of candidemia, and numerically higher in-hospital mortality than non-obese patients. In addition, obese patients were more likely to receive echinocandins and to have infectious diseases consults than non-obese patients. In the total population, risk factors for clinical failure in patients with Candida bloodstream infection were hematologic malignancy, presence of mechanical ventilation, and baseline WBC, respiratory rate, and temperature. Information from larger cohorts would be beneficial to further delineate the impact of obesity and the specific risk factors for clinical failure in patients with Candida bloodstream infections.

\section{ACKNOWLEDGEMENTS}

Funding. No funding or sponsorship was received either for the study or article publication. The Rapid Service Fee was funded by the authors.

Authorship. All named authors meet the International Committee of Medical Journal Editors (ICMJE) criteria for authorship for this article, take responsibility for the integrity of the work as a whole, and have given their approval for this version to be published.

Prior Presentation. This study was previously presented at ID Week 2018.
Disclosures. Katie E. Barber is a consultant and/or speaker for Paratek Pharmaceuticals and Tetraphase Pharmaceuticals. Jamie L. Wagner, Jennifer M. Miller, Emily A. Lewis, and Kayla R. Stover report no conflicts of interest to declare.

Compliance with Ethics Guidelines. The presented study received approval from The University of Mississippi Office of Research Integrity Institutional Review Board and conformed with the Helsinki Declaration of 1964 (as revised in 2013) concerning human and animal rights. On account of the investigation being carried out through retrospective review of medical records, ethics approval was not required because of no foreseeable impact on the rights and/or welfare of subjects involved. Consent from study participants was additionally not obtained due to the study solely involving retrospective review of medical records.

Data Availability. The datasets during and/ or analyzed during the current study are available from the corresponding author on reasonable request.

Open Access. This article is licensed under a Creative Commons Attribution-NonCommercial 4.0 International License, which permits any non-commercial use, sharing, adaptation, distribution and reproduction in any medium or format, as long as you give appropriate credit to the original author(s) and the source, provide a link to the Creative Commons licence, and indicate if changes were made. The images or other third party material in this article are included in the article's Creative Commons licence, unless indicated otherwise in a credit line to the material. If material is not included in the article's Creative Commons licence and your intended use is not permitted by statutory regulation or exceeds the permitted use, you will need to obtain permission directly from the copyright holder. To view a copy of this licence, visit http://creativecommons.org/licenses/bync/4.0/. 


\section{REFERENCES}

1. Weiner LM, Webb AK, Limbago B, et al. Antimicrobial-resistant pathogens associated with healthcare-associated infections: summary of data reported to the National Healthcare Safety Network at the Centers for Disease Control and Prevention, 2011-2014. Infect Control Hosp Epidemiol. 2016;37(11):1288-301.

2. Magill S, Edwards J. Multistate point-prevalence survey of health care-associated infections. New Engl J Med. 2014;370(13):1198-208.

3. Wisplinghoff H, Ebbers J, Geurtz L, et al. Nosocomial bloodstream infections due to Candida spp. in the USA: species distribution, clinical features and antifungal susceptibilities. Int J Antimicrob Agents 2014;43(1):78-81.

4. Gudlaugsson O, Gillespie S. Attributable mortality of nosocomial Candidemia, revisited. Clin Infect Dis. 2003;37(9):1172-7.

5. Segal BH, Herbrecht R, Stevens DA, et al. Defining responses to therapy and study outcomes in clinical trials of invasive fungal diseases: mycoses study group and European organization for research and treatment of cancer consensus criteria. Clin Infect Dis. 2008;47(5):674-83.

6. Finkelstein EA, Trogdon JG, Cohen JW, et al. Annual medical spending attributable to obesity: payer- and service-specific estimates. Health Aff. 2009;28(5):w822-31.

7. Hales CM, Carroll MD, Fryar CD, Ogden CL. Prevalence of obesity among adults and youth: United States, 2015-2016. Centers for Disease Control and Prevention National Center for Health Statistics Data Brief 2017;288.

8. Pappas PG, Kauffman CA, Andes DR, et al. Clinical practice guideline for the management of Candidiasis: 2016 update by the Infectious Diseases Society of America. Clin Infect Dis. 2016;62:e1-50.

9. Alobaid AS, Wallis SC, Jarrett P, et al. Effect of obesity on the population pharmacokinetics of fluconazole in critically ill patients. Antimicrob Agents Chemother. 2016;60(11):6550-7.

10. Maseda E, Grau S, Luque S, et al. Population pharmacokinetics/pharmacodynamics of micafungin against Candida species in obese, critically ill, and morbidly obese critically ill patients. Crit Care. 2018;22(1):94.

11. Wasmann RE, Smit C, Ter Heine R, et al. Pharmacokinetics and probability of target attainment for micafungin in normal-weight and morbidly obese adults. J Antimicrob Chemother. 2019;74:978-85.

12. Centers for Disease Control and Prevention. Defining adult overweight and obesity. Last reviewed April 11, 2017. https://www.cdc.gov/ obesity/adult/defining.html. Accessed 29 May 2019

13. Cretella D, Barber KE, King ST, Stover KR. Comparison of susceptibility patterns using commercially available susceptibility testing methods performed on prevent Candida spp. J Med Microbiol. 2016;65(12):1445-51.

14. Tortorano AM, Prigitano A, Lazzarini C, et al. A 1-year prospective survey of candidemia in Italy and changing epidemiology over one decade. Infection. 2013;41:655-62.

15. Pfaller MA, Andes DR, Diekema DJ, et al. Epidemiology and outcomes of invasive candidiasis due to non-albicans species of Candida in 2,496 patients: data from the Prospective Antifungal Therapy (PATH) registry 2004-2008. PLoS One. 2014;9: e101510.

16. Tedeschi S, Tumietto F, Giannella M, et al. Emilia Romagna Candida Network. Epidemiology and outcome of candidemia in internal medicine wards: a regional study in Italy. Eur J Intern Med 2016;34: 39-44.

17. Tukenmez Tigen E, Bilgin H, Perk Gurun H, et al. Risk factors, characteristics, and outcomes of candidemia in an adult intensive care unit in Turkey. Am J Infect Cont. 2017;45:e61-3.

18. Zaoutis TE, Argon J, Chu J, Berlin JA, Walsh TJ, Feudtner C. The epidemiology and attributable outcomes of candidemia in adults and children hospitalized in the United States: a propensity analysis. Clin Infect Dis. 2005;41: 1232-9.

19. León C, Ruiz-Santana S, Saavedra P, et al. A bedside scoring system ("Candida score" for early antifungal treatment in nonneutropenic critically ill patients with Candida colonization. Crit Care Med. 2006;34(3):730-7.

20. Andes DR, Safdar N, Baddley JW, et al. Impact of treatment strategy on outcomes in patients with candidemia and other forms of invasive candidiasis: a patient-level quantitative review of randomized trials. Clin Infect Dis. 2012;54:1110-22.

21. Atamna A, Elis A, Gilady E, Gitter-Azulay L, Bishara J. How obesity impacts outcomes of infectious diseases. Eur J Clin Microbiol Infect Dis. 2017;36: 585-91. 
22. Lizza BD, Rhodes NJ, Esterly JS, Toy C, Lopez J, Scheetz MH. Impact of body mass index on clinical outcomes in patients with gram-negative bacteria bloodstream infections. J Infect Chemother. 2016;22:671-6.
23. Nguyen AT, Tsai C, Hwang L, Lai D, Markham C, Patel B. Obesity and mortality, length of stay and hospital cost among patients with sepsis: a nationwide inpatient retrospective cohort study. PLoS One. 2016;11(4):e0154599. 